Pasado y Memoria

ISSN: 2386-4745

Núm. 23, 2021, pp. 260-282

https://doi.org/10.14198/PASADO2021.23.11

Estudios

\title{
La voz de una autoridad heterodoxa sobre el amor en el primer franquismo. Los consultorios sentimentales de Amparo Rivelles
}

\author{
The voice of a heterodox authority on love in the \\ First Francoism. Amparo Rivelles' sentimental advice \\ columns
}

\author{
Álvaro Álvarez Rodrigo \\ Universitat de València, España \\ alvaro.alvarez@uv.es \\ https://orcid.org/0000-0003-1126-7408
}

Recibido: 15/11/2020

Aceptado: 19/02/2021

Cómo citar este artículo: ÁlVAREZ RODRIGO, Álvaro (2021). La voz de una autoridad heterodoxa sobre el amor en el primer franquismo. Los consultorios sentimentales de Amparo Rivelles. Pasado y Memoria. Revista de Historia Contemporánea, (23), pp. 260-282, https:// doi.org/10.14198/PASADO2021.23.11

\section{Resumen}

Entre 1948 y 1952, el semanario cinematográfico Primer plano publicó un consultorio sentimental firmado por la actriz Amparo Rivelles. La estrella española más popular del momento se convertía así en consejera sobre la moral, el noviazgo y los usos amorosos entre los jóvenes; una cuestión que el Régimen consideraba como una pieza fundamental en la regulación de las relaciones de género. Se trata de un consultorio singular, alejado de la gravedad, el dramatismo y la grandilocuencia de otros, surgidos en diversos medios periodísticos a raíz de la buena acogida de público que estas secciones gozaron durante aquellos años. El presente artículo analiza las implicaciones de unos textos en los que su autora se permitía bromear, cuando no contradecir de algún modo los códigos normativos, que en añadidura chocaban con su imagen de estrella constituida como un modelo heterodoxo de feminidad frente al ideal franquista. 
Palabras clave: Amparo Rivelles; Estrellas cinematográficas; Primer Franquismo; Educación sentimental; Género; Revistas cinematográficas; Medios de Comunicación.

\begin{abstract}
The weekly film magazine Primer plano published a sentimental advice column signed by the actress Amparo Rivelles from 1948 to 1952. The most popular celebrity of the moment thus became an advisor on morals, courtship and love practices among young people; an issue the Regime considered as a fundamental piece in the regulation of gender relations. It was a special sentimental advice column, far from the seriousness, the dramatic tone, and the grandiloquence of others, which emerged in several mass media, as a result of the public positive reception those sections enjoyed at the time. This paper analyses the implications of said texts whose authoress allowed herself to joke, if not to rather contradict those normative codes, which rather clashed with her image of a star boasting an heterodox model of femininity as opposed to the Francoist ideal.
\end{abstract}

Keywords: Amparo Rivelles; Movie Stars; First Francoism; Sentimental Education; Gender; Film Magazines, Mass Media.

\title{
Introducción
}

El 28 de marzo de 1948, la revista cinematográfica Primer plano comenzó a publicar un consultorio sentimental firmado por "Amparito Rivelles» ${ }^{1}$ y encabezado por una fotografía suya. Durante más de cuatro años, la columna fue una sección fija del semanario, si bien, pasado un tiempo, no siempre acudió a su cita con total regularidad. En su sección, la actriz, probablemente en esos momentos la estrella española más popular y carismática, respondía a las cartas que los lectores le dirigían acerca de temas diversos, pero principalmente de índole amorosa. Amparo Rivelles se convertía así en consejera de una cuestión tan importante para el régimen franquista como era la moralidad y la educación sentimental, especialmente de las mujeres. Sin embargo, la actriz parecía no ser consciente de la seriedad que el asunto merecía, ni con frecuencia ofrecía a sus fans el mismo tipo de consejos que el resto de los consultorios, tan en boga en aquellos años.

El propósito de este artículo no es analizar cuáles eran los conocimientos, opiniones y preocupaciones que afectaban a los españoles de ambos sexos sobre esta materia, aunque algo de ello quede aquí reflejado; sino la propia

1. En la época, el empleo de diminutivos en los nombres de actrices españolas era una práctica frecuente, a diferencia de lo que sucedía con sus colegas varones. Un uso del lenguaje indicativo de la mirada paternalista que a menudo se dirigía hacia ellas. 
existencia de un consultorio sentimental un tanto singular. Nos interesan más las respuestas que brinda la actriz que los problemas que se le plantean, en tanto que contribuyen a convertir a la estrella cinematográfica en un modelo heterodoxo respecto al ideal nacionalcatólico de feminidad, que pone en evidencia las tensiones y contradicciones creadas por las políticas franquistas de género. Nos situamos, pues, en el plano de una historia cultural que desde los llamados star studies propone aproximarnos a los procesos de creación de identidades colectivas, y, en concreto, a las de género.

Se parte de la conceptualización de la estrella cinematográfica como una representación cultural, como una imagen compleja, intertextual y polisémica, que se desarrolla y cambia con el paso del tiempo (Dyer, 2001). Está construida por una panoplia de fuentes, que van desde las películas hasta cuanto en relación con su carrera profesional y su vida, pública o privada, aparece en los medios periodísticos, promocionales, literarios... o incluso por los rumores, que pueden ser también rastreados en las fuentes. En nuestro caso, para revelar la imagen estelar de Amparo Rivelles se ha recurrido fundamentalmente a su filmografía y a las revistas cinematográficas del período, tales como Primer plano, Radiocinema, Cámara, Fotogramas e Imágenes, junto a otros medios periodísticos como el diario $A B C$, el Noticiario Cifesa o el No-Do.

Sin embargo, la fuente primaria concreta sobre la que se focaliza este artículo son las decenas de consultorios firmados por Amparo Rivelles en la revista Primer plano. La publicación estaba editada por la cadena Prensa del Movimiento, y durante la primera mitad de la década de los cuarenta funcionó como portavoz oficial del régimen en materia de cinematografía. A partir de entonces, aunque sin perder su vocación de servir de orientador ideológico y estético, se abrió progresivamente a contenidos más populares (Nieto Ferrando, 2009). Entre ellos, el citado consultorio, en el que la actriz atendía a tres o cuatro cartas enviadas por sus admiradores, a las que, tras la transcripción de solo un pequeño fragmento, ofrecía su respuesta.

No obstante, antes de adentrarnos de lleno en esta documentación, parece oportuno trazar los componentes fundamentales de la imagen de la actriz, aunque en este texto tan solo sea posible plantear una impresión simplificada ${ }^{2}$.

\section{«La estrella de oro» de los años cuarenta, un heterodoxo modelo de feminidad}

En 1950, Amparo Rivelles (1925-2013) cumplió veinticinco años y se encontraba en el punto más alto de su popularidad. Su carrera cinematográfica se

2. Sobre la construcción de la imagen de Amparo Rivelles como estrella cinematográfica en la España de los años cuarenta y cincuenta, véase: Álvarez Rodrigo, en prensa. 
había iniciado a principios de la década anterior, avalada por la herencia artística de sus padres, los reconocidos intérpretes de la pantalla y de la escena Rafael Rivelles y María Fernanda Ladrón de Guevara. Tras unas primeras películas, obtuvo un contrato excepcional con la compañía Cifesa, al alcance de muy pocos intérpretes (Fanés, 1982: 111).

Malvaloca (Luis Marquina, 1942) le había abierto las puertas del éxito a los diecisiete años, pero su rápida celebridad se debió en buena medida a su romance con el también actor Alfredo Mayo, el gran galán cinematográfico del momento y arquetipo de héroe franquista. Ella transmitía la imagen de una chica moderna, tanto por sus interpretaciones como por su aspecto y su manera de comportarse. En un contexto de extremas dificultades económicas y de fuerte represión moral, su forma de vida debió de resultar sumamente atractiva para muchas chicas de su edad: alegre, bromista, desenfadada, coqueta, que fuma y viste a la moda... y que se maneja con una cierta autonomía personal y económica.

Mientras, la pareja cinematográfica del momento se convirtió en modelo de noviazgo oficial, que aparentemente cumplía con los códigos de una relación que es entendida como la antesala del matrimonio. Sin embargo, Rivelles canceló su boda con el novio más codiciado por las españolas a pocos días de subir al altar. La ruptura, a pesar de ser ignorada por la prensa, no debió de pasar desapercibida y reforzaría esa imagen de joven independiente que ya se había comenzado a labrar. La manera en que en los años siguientes conduciría sus relaciones sentimentales abundarían en este sentido, aunque paradójicamente fuera intensificada por su silenciamiento en los medios, que a la vez daban pie a que se especulara con sus romances. Entre ellos, con Jorge Mistral, el nuevo gran seductor cinematográfico español, su pareja de cartel en un par de películas, que al parecer sí tuvo lugar más allá de la ficción.

Paralelamente, ofrecía en la pantalla y fuera de ella una imagen cada vez más sensual y erotizada, hasta el punto de que fue catalogada como «nuestra pin-up número $1 »^{3}$. Es incuestionable que existe una reificación de su cuerpo; pero también que se toma consciencia de que el proceso de empoderamiento que está experimentando procede en buena parte de su representación cada vez más sexualizada. Encarna a heroínas fuertes, un tipo de personajes que destaca en el cine español de los cuarenta, en películas en las que, como señala Jo Labany (2016: 167-168), ellas son las seductoras y ellos los seducidos, "whose result is the projection on to women of a verbal and physical freedom and vitality that makes them the agents as well as the objects of desire».

3. «Amparito Rivelles». Primer plano n. 357, 17 de agosto de 1947. 
Por otra parte, vale la pena recordar el fecundo debate generado a partir del artículo de Laura Mulvey (2001) publicado originalmente en 1975, que planteaba que en el cine clásico la cámara adoptaba la posición del varón. Desde este punto de vista, el cuerpo de la mujer quedaba cosificado y servía tan solo de objeto de satisfacción del deseo heterosexual masculino. Distintos trabajos han reformulado esta propuesta en la que el placer de mirar se escindía entre una actitud activa (masculina) y pasiva (femenina). Entre ellos, Jackie Stacey se preguntaba cómo miran las espectadoras a las estrellas femeninas y concluía que su cuerpo también puede convertirse en fuente de placer para ellas, no solo como deseo homoerótico, de atractivo sexual, sino por la fascinación generada por el poder y la sofisticación de otra mujer y por la confianza en sí misma (Stacey, 1994).

Sin duda, la proyección de Rivelles como un icono de moda y consumo alentaba asimismo esta imagen empoderada y atractiva. Su modo de vida y su apariencia física, en un contexto de graves carestías, despertaría la admiración o la envidia de muchas espectadoras, que anhelarían ser como ella. Rivelles no ocultaba su alto nivel de vida y confesaba sin pudor en una entrevista que compraba sin mesura ropa y calzado:

«Dedico todo mi dinero a la ropa. Me gasto un dineral en vestidos, a los que siempre he tenido una gran afición. Otra de mis debilidades son los zapatos.

¡Tengo tantos!

$-i$ Cuantos?

-No te asustes: 114 pares.» ${ }^{4}$

Era una joven con independencia económica para disponer de su dinero, en un momento en que el consumo femenino recibía críticas misóginas como superficial y dilapidador, mientras que ella expresaba que comprar era un placer personal, y no un mero medio para agradar al hombre que la mira. Una actitud en cierto modo desafiante, que pone de manifiesto que el consumo no tiene por qué ser un acto meramente pasivo, sino que puede suponer una negociación activa y una transformación de identidades (Stacey, 1994: 204-208). En cualquier caso, como afirma Victoria De Grazia (1996), más allá del debate sobre si el consumo es una vía de empoderamiento femenino o de opresión, estas prácticas tienen que ser analizadas en cada contexto y sistema político, en el que un mismo acto puede tener significados distintos, con relación a las expectativas o necesidades. De modo que no se debe perder de vista que el

4. GARCÍA DE LAPUERTA. «La actualidad cinematográfica presentada por Risler». Primer plano, 220, 31 de diciembre de 1944. 
consumo era uno de los motivos esgrimidos por la dictadura franquista como causa de la relajación de la honestidad femenina (Roura, 2005, 107).

«-Pero con entera sinceridad: dígame, Amparito, ¿es usted verdaderamente una mujer romántica, capaz de casarse con un hombre sólo por el amor?

-No me casaría jamás por otra cosa.

-Ahora, otra pregunta indiscreta: ¿cuánto gana usted diariamente?

-Al lado de mi madre mucho más que en el cine.

-Y usted cree que hay en la tierra un hombre, usted lo ha dicho antes, y perdóneme que emplee sus mismas palabras, «tan suicida», que tenga el valor de casarse con una mujer como usted, acostumbrada a ganar, y me supongo que a gastar, tanto dinero? ...»

Era ella misma la que alimentaba una imagen moderadamente irreverente e indómita, que no estaba dispuesta a someterse al vínculo conyugal. Así queda patente en un reportaje en el que se pregunta a cuatro actrices qué opinan sobre el matrimonio, en el que todas ellas tratan de alguna manera de evitar una situación comprometida. Sin embargo, Rivelles adopta una actitud abiertamente descreída y sarcástica respecto al matrimonio. El periodista la entrevista durante la pausa de un rodaje y en un momento dado, en el estudio se reclama un anillo para que lo luzca un personaje. Un hombre se brinda a prestarlo y el reportero apunta que su gesto equivale a afirmar: «iSoy casado, señorita!...». Y a continuación narra la elocuente reacción de la estrella:

«Es entonces cuando Amparito pliega la comisura de sus labios en una mueca descarada de compasión:

-Pobrecillo -se la oye comentar. Y uno se ha de quedar con las ganas de preguntar a Amparito:

-Oye, Amparo ¿crees en el matrimonio?

La encuesta, perdón, quedó coja. ${ }^{6}$

Quien así habla lo hace desde la autoridad que le concede ser la «Estrella de oro de 1949», según los lectores de Primer plano ${ }^{7}$. En esta tercera edición, Rivelles ocupa el primer puesto en popularidad. El año anterior, fue Aurora Bautista la primera, probablemente debido al extraordinario éxito de Locura de amor (Juan de Orduña, 1948), mientras que Rivelles quedó en segundo lugar ${ }^{8}$. En la primera ocasión en que se celebró la consulta entre los lectores, Amparo Rivelles fue galardonada con la «Estrella de oro de $1947 »^{9}$. Unas encuestas que,

5. NARBONA, Rafael. «Amparito Rivelles ya no se quiere casar». ABC, 5 de enero de 1946.

6. BELTRÁN, Fernando. «Amor, amor, Las estrellas opinan sobre el matrimonio». Cámara 170, 1 de febrero de 1950 .

7. «Estrella de oro 1949». Primer plano, 492, 18 de marzo de 1950.

8. «Estrella de oro 1948». Primer plano, 445, 24 de mayo de 1949.

9. «Estrella de oro 1947». Primer plano, 395, 9 de mayo de 1948. 
aunque no tenga un gran valor demoscópico, sirven para corroborar el atractivo de la actriz. A finales de 1948, había vuelto a firmar con Cifesa un contrato en exclusiva (Fanés, 1982: 186-187). A pesar de su juventud, parece haber entrado en una fase de madurez como actriz, a través de sus papeles en recreaciones históricas como La leona de Castilla (Juan de Orduña, 1951) o Alba de América (Juan de Orduña, 1951). Estos títulos rompen en parte con esa imagen sensual, sobre la que erige como una figura mayestática, que ocupa un lugar de honor en el firmamento cinematográfico español. El nacimiento de su única hija, omitido por los medios habida cuenta de que era madre soltera, será uno de los factores que alterarán su trayectoria profesional, hasta el punto de que en 1957 marchó a México para continuar allí su carrera, y no regresó a España hasta más de veinte años después. No obstante, su gran carisma y popularidad todavía seguían intactos en los años en que se publicaba su consultorio sentimental, a través del que mantenía un contacto estrecho con sus fans.

\section{Un consultorio tan típico como excepcional}

Los consultorios sentimentales gozaron de una gran difusión en los medios de comunicación españoles en los años cuarenta y cincuenta, especialmente en la radio y en las revistas dirigidas a un público femenino. Tras la Guerra Civil, vivió una etapa dorada que se relaciona con la voluntad de la Dictadura de propagar contenidos que sirvieran para moldear a las mujeres según el canon de feminidad franquista. Legitimaban su regreso al hogar y promovían las actitudes de sumisión al varón y la abnegación, a la vez que les ofrecían recompensas emocionales y paños calientes para los problemas cotidianos (Blanco Fajardo, 2016).

Pero al mismo tiempo que promovían un modelo normativo, eran también expresión de las resistencias a aceptarlo a través de los problemas que exponían las remitentes de las cartas. Se convertían así en un espacio de negociación entre el discurso público y privado, en «una trama polifónica de pareceres que iba orquestando un estilo sentimental que contenía tanto una sutil gama de resistencias cotidianas a lo normativo, como obediencias a las normas de la feminidad» (Medina Doménech, 2013: 202-203). El análisis de estas cartas, entendidas como testimonio de una identidad subjetiva, exponen a menudo «vidas infames», que, aunque tengan que ser reconducidas, expresan una disidencia. Al romper el silencio y sacar a la luz una intimidad aberrante, el acto de escritura puede ser entendido como un gesto de rebeldía, como una línea de fuga del discurso hegemónico, que lo enfrentan a sus propias contradicciones (Sánchez Sánchez, 2013). 
En el consultorio intervienen dos actores principales, el consejero y el aconsejado. Entre ambos se crea la ilusión de una comunicación interpersonal, en una interacción en el que se dirimen conductas ligadas a la intimidad de los individuos (Garis, 2010). Un 'dialogo' que se entabla con los lectores como testigos, que son a quienes en última instancia va dirigido el mensaje. A menudo las cartas no se publican o, como sucede en Primer plano, solo se transcribe un fragmento. Aquello que se considera de interés es la respuesta del consejero, con lo que se añade un elemento más de manipulación en su contenido. El remitente a veces firma simplemente con las iniciales, el nombre de pila, o bien añade también el apellido (real o inventado) o, con mayor frecuencia, utiliza un seudónimo. Frente a los alias arrebatadores que abundan en otros consultorios, con expresiones como "Un corazón sangrando», «Una desesperada», «Una desconsolada» o «Una que sufre en silencio» (Balsebre y Fontova, 2018: 431437), en las cartas que se dirigen a Rivelles la identificación de los remitentes suele denotar un menor fervor, con apelativos que no acostumbran a contener una mayor dosis de arrobamiento que "Una romántica», «Mariposa azul», «La violeta misteriosa» o «Un jurista enamorado». Otro indicio de su carácter liviano, tal como después se expondrá.

De entre los consultorios de la época, «El consultorio de la mujer de Elena Francis», cuyas emisiones comenzaron en noviembre de 1947 y se mantuvieron en antena diariamente de lunes a viernes durante diecinueve años, fue el que alcanzó una mayor popularidad (Soto Viñolo, 1995: 39). Frente a los publicados por los medios escritos, contaba con la ventaja de poder llegar a un público más amplio, tanto por las barreras culturales que suponía el elevado índice de analfabetismo como por las de carácter económico, ya que eran frecuentes las audiciones colectivas, que no requerían disponer de un aparato de radio propio (Blanco Fajardo, 2016). La comparación del «Consultorio sentimental» de Amparo Rivelles, aunque sea solo de forma somera, con este y otros de la época es significativa ${ }^{10}$.

Nos encontramos ante un tipo particular de consultorios en el que quien adopta el papel de consejero no es una figura de autoridad reconocida por su saber y competencia como experto en una materia, normalmente por su categoría académica o religiosa, ya fueran médicos, licenciados universitarios

10. Como elementos de comparación, se ha consultado el «Consultorio sentimental» publicado por la Revista para la mujer Y, editada por la Sección Femenina en la primera mitad de la década de los cuarenta, y las referencias bibliográficas sobre el citado «Consultorio de la mujer de Elena Francis» o las cartas de la revista Meridiano femenino entre 1946 y 1960, cuyo público era fundamentalmente mujeres de clase media entre los veinte y los cuarenta años (Medina Doménech, 2013), entre otros estudios. 
o sacerdotes. En estos casos, son artistas y otros personajes famosos los que adoptan una posición de guía, y resultan confiables precisamente porque son populares. Solo cuando el consejero es una figura célebre se publica su fotografía, con lo que se le despoja del carácter enigmático que normalmente ostenta el asesor sentimental. Es precisamente el conocimiento de la vida privada de estos ídolos, el motivo por el que los lectores se animan a pedirles consejos, a los que ellos responden a partir de su experiencia personal (Garis, 2010). Visto el perfil trazado más arriba sobre la actriz, las implicaciones que ello conlleva serán relevantes. Máxime cuando Amparo Rivelles no recurre en sus respuestas a referencias externas de autoridad, y no cita en sus textos otras obras, ya sean novelas, clásicos tan del gusto del Régimen como La perfecta casada de fray Luis de León o manuales de formación para la mujer que se distribuían ampliamente en aquellos años (Di Febo, 2005).

Pero al margen de esta cuestión que después abordaremos, un primer factor para tener en cuenta es que se trata de una persona a la que las aconsejadas conocen, o creen conocer, de manera fehaciente y a quien pueden identificar. Es más, nadie puede dudar de que su consejera es una persona real. En el caso de programa radiofónico antes mencionado, sabemos que Elena Francis nunca existió, y que incluso la voz del personaje fue interpretada por diferentes locutoras a lo largo de décadas sin solución de continuidad. Sus consejos fueron también obra de diferentes autores, hombres y mujeres; aunque su primera guionista y en cierta manera creadora del personaje fue Ángela Castells, quien, hasta 1953, fue la encargada de ponerlo al frente de una «escuela de formación moral» acorde con los principios del Régimen. (Balsebre y Fontova, 2018: 27-36).

Respecto al consultorio que aquí nos ocupa, una de las primeras cuestiones por las que podemos preguntarnos es la autoría real de los textos, si damos por cierto que es Amparo Rivelles quien los escribe o si simplemente los firma. Sin embargo, a la luz de los documentos a los que se ha tenido acceso, no es posible disponer de una respuesta concluyente. De todos modos, desde la perspectiva planteada en la investigación ello carece de importancia real. Sea quien sea su autor, es a ella a quien son atribuidos y por tanto se configuran como un factor más en la construcción de su imagen, puesto que se dirige en primera persona a sus seguidores. Si estos dudaban o no de la sinceridad de sus palabras, se nos escapa. A partir de los indicios de los propios textos y del conocimiento adquirido sobre la actriz, se podría conjeturar tanto su autenticidad como su contrario. Si bien, a nuestros efectos son auténticas porque expresan la voz de la estrella y ella las asume como tales. 
En diversas ocasiones, Rivelles afirma con rotundidad que escribe personalmente la columna. Se suele quejar del enorme volumen de cartas que recibe y de que a menudo se ve superada para responderlas todas. Advierte que no admite cartas personales, porque tendría que contratar «falsas Amparitos» para poder completar la tarea. En una de las entrevistas cuyo propósito parece ser la promoción de la sección, la periodista la sorprende durante los descansos del rodaje escribiendo a máquina para atender la montaña de cartas. Cuenta que le llegan más de doscientas misivas a la semana, de las que descarta muchas por no tener «nada de sentimental»y otras muchas las pasa a su secretaria por tratarse de peticiones de autógrafos ${ }^{11}$.

Tan solo conocemos, por tanto, una mínima parte del conjunto, pero puede servirnos de referencia aproximada un estudio sobre la correspondencia de fans de la actriz italiana Claudia Cardinale durante la posguerra mundial (Buckley, 2009). En primer lugar, cabe indicar que su volumen era utilizado para monitorizar la popularidad de las estrellas, y que era frecuente que se contratara ayudantes para que las asistieran. De todos modos, la comparación no puede ser precisa porque se trata de correspondencia privada a la estrella y no de un consultorio sentimental. Sin embargo, se atisban bastantes coincidencias por los comentarios que vierte Rivelles en sus respuestas, por ejemplo, sobre las declaraciones de amor que le dedican sus admiradores o el fastidio que le producen las misivas de aspirantes a actriz o a actor.

Por su parte, Jackie Stacey, nos advierte de dos limitaciones metodológicas al adentrarnos en las páginas de cartas de fans, no específicamente en un consultorio sentimental, como fuente histórica. La primera es que muchas de ellas están escritas en respuesta a artículos que aparecen en la revista, que por tanto está sugiriendo la agenda de temas. Un segundo problema tiene que ver con que los documentos que se recogen solo representan a una parte de los espectadores, mientras que los grupos marginales estarían ausentes (Stacey, 1994: 54-55).

Volviendo sobre la autoría de nuestro consultorio, puede haber motivos para la desconfianza. Con todo, a partir de los indicios de que disponemos, debió de darse una situación intermedia. No parece probable que, a pesar de sus propias afirmaciones, Amparo Rivelles asumiera personalmente una tarea tan ingente. Sin embargo, tampoco parece verosímil que la actriz cediera a la revista el control de su imagen, que tanto cuidaba, sin supervisión. Por ello, podemos inclinarnos a pensar que, si bien en ocasiones podría ser ella misma

11. MORALES, Sofía. «Amparito, frente a la máquina». Primer plano, 514, 20 de agosto de 1950. 
quien escribiera la columna, otras veces serían sus asistentas (ya en algún reportaje se informa de que tiene contratadas dos secretarias, lo que da cuenta de su estatus) las que se encargarían del consultorio a partir de sus instrucciones. En cualquier caso, hay un cierto aire de la personalidad de Rivelles que sí se deja notar en todas ellas, y, lo que es más importante, que así era percibido por una gran mayoría de lectores, a los que no sonaría impostada esa voz en primera persona.

Primer plano es la única revista cinematográfica de la que se tenga constancia que durante estos años concedió un espacio en sus páginas a un consultorio sentimental firmado por una estrella. Una noticia que la revista anuncia como relevante, dada la personalidad de la consejera:

«A partir del próximo número, los lectores de PRIMER PLANO tendrán una grata sorpresa. La gran actriz del cine español Amparito Rivelles ha accedido a nuestros deseos de encargarse de la nueva sección del «Consultorio sentimental», respondiendo en nuestras páginas aquellas cartas que le dirijan nuestros lectores y lectoras. Amparito Rivelles, que es una gran inteligencia y una gran sensibilidad, nos honra con su debut como escritora en un género epistolar en el que estamos seguros le acompañará la popularidad que tiene en la pantalla.» ${ }^{12}$

Ese carisma que se le atribuye procedería de su condición de estrella, puesto que solo cabe pensar que los conocimientos que comparte son fruto de la interiorización en los personajes que ha encarnado y de unas vivencias propias que no han tenido ocasión de experimentar los lectores y lectoras. Un consultorio que, además, de tanto en tanto no aborda solo cuestiones sentimentales y se llega al extremo de lo grotesco al erigirse en experta de asuntos bien diversos. Así, le explica a un argentino qué trámites hay que realizar para conseguir la nacionalidad española o se convierte en especialista en grafología, una técnica que en aquellos años recibía atención en muchos medios. Eso unido a sus consejos sobre belleza facial, moda, decoración del hogar, etcétera. De manera que si lo comparamos con la Revista para la mujer $Y$, se observa que ella misma atendía a preguntas que la publicación de Falange repartía entre secciones diferentes atendidas por sus respectivos especialistas, como era el consultorio sentimental propiamente dicho, el grafológico, el jurídico o el de higiene y belleza. Tal vez este último sería, habida cuenta de lo ya indicado sobre su configuración como icono de moda y consumo, el único al que no se podría objetar su posición de autoridad.

12. «Amparito Rivelles escribirá para Primer plano». Primer plano, 388, 21 marzo de 1948. 
Vale la pena también indagar sobre quiénes participan en el consultorio, y si son cartas auténticas o ficticias, aunque la conclusión no pueda ser más que tentativa. Si lo comparamos con el consultorio de Elena Francis, disponemos del testimonio de uno de sus guionistas, que explica que en ocasiones inventó algunas cartas para forzar una mayor variedad en los contenidos e introducir temas nuevos ${ }^{13}$. Sin embargo, aquí, aunque sin poder descartarlo, no parece que existieron motivos para esta práctica.

A diferencia de la mayoría de los consultorios radiofónicos y de revistas femeninas, a Amparo Rivelles escriben tanto hombres como mujeres. Quizá más las segundas, aunque no es menospreciable el número de los primeros. Puede resultar sorprendente, por contradictorio con el ideal de masculinidad franquista, que algunos varones expongan públicamente, y más aún sometan al juicio de una mujer, sus inseguridades respecto a las relaciones sentimentales. Una peculiaridad que puede deberse al gran atractivo de la consejera por su propia condición de estrella de cine, junto a otro rasgo destacado de los remitentes. Pues una característica común a ambos sexos es que mayoritariamente son muy jóvenes, con frecuencia adolescentes. Tampoco nada inusual, pues también la edad más habitual entre las remitentes de cartas al consultorio de Elena Francis era los diecisiete años (Balsebre y Fontova, 2018: 163), e igual sucede con los de la Revista para la mujer Y. Sin duda, esa diferencia de edad entre la estrella y sus admiradores contribuiría a la fascinación por una personalidad cautivadora e inalcanzable, que era identificada como modelo de feminidad (Stacey, 1991). En términos generales, según apunta Annette Kuhn (Kuhn, 2002: 133-134) para los años treinta, los adolescentes serían el público más impresionable por el cine, aquel al que se proveía con más facilidad de un espacio para soñar y que a la vez inspiraba sus conversaciones reales. Ello puede confirmar por qué son tan jóvenes muchos de quienes escriben al consultorio y esa sensación de irrealidad que transmiten las cartas, de las que Rivelles se ríe con disimulo, al tiempo que alimenta sus sueños románticos:

No se meta en complicaciones de noviazgos y termine sus carreras. Después, ¡Dios dirá! No olvide que la calle, las tiendas, los tranvías, los cines, los teatros..., están llenos de mujeres. ¡Hay montones! ${ }^{14}$

Me parece, querida amiga, para empezar, que te has enamorado demasiado pronto, ¿Lo crees? Claro que enamorarse es tan hermoso... Pero, en fin, lo difícil es saber si se está enamorada de verdad o por las circunstancias. Porque

13. Juan Soto Viñolo fue guionista de este consultorio durante dieciocho años en la última época del programa radiofónico (Soto Viñolo, 1995: 193).

14. RIVELLES, Amparito. «Consultorio sentimental». Primer plano, 454, 26 de junio de 1949. 
¡es tan atractivo esto que te ocurre a ti!... Vamos, de heroína de novela romántica de las buenas ${ }^{15}$.

Se trata de unos textos muy relevantes por diferentes motivos, pero de cuyo análisis es difícil extraer conclusiones claras, porque uno de sus rasgos más destacados es su carácter ambiguo y contradictorio. Una impresión similar expresa Carmen Martín Gaite al acercarse a estos consultorios sentimentales tan comunes en la época que califica de enrevesados en cuanto son ilustradores de la «conducta amorosa y sus titubeos» de unos jóvenes «que se aventuraban a tientas, entre la ignorancia y la zozobra» (Martín Gaite, 2002: 165). Excede a los propósitos de este trabajo el análisis de las actitudes sociales que reflejan los fragmentos de las cartas publicadas, y tan solo abordaremos de algunos aspectos en su relación con la actriz.

\section{Consejos desenfadados y contradictorios ante los vaivenes del amor}

Si, como ya se ha apuntado, el objetivo de estos consultorios era la moralización de las costumbres y la difusión de unos determinados roles de género, podemos dudar de hasta qué punto la elección de la consejera fue acertada. Sí, desde luego, en cuanto a su relevancia e incluso a su ascendencia para los lectores, puesto que la personalidad de Rivelles lo dotaba de un interés del que otros carecían. Pero es más discutible en cuanto a que no se trataba de una figura pública modélica de la ortodoxia moral que el régimen trataba de imponer. De aquí surgen buena parte de las contradicciones subyacentes.

Por un lado, debido a la falta de coherencia entre las respuestas. Igual orienta a un lector hacia una determinada dirección que hacia su contraria, e incluso esa misma ambigüedad puede llegar a darse en un mismo texto. En ocasiones no duda de apostar por el mito romántico como ideal amoroso, y en otras desmitifica entre bromas ese horizonte anhelado por tantas jovencitas. Así, por citar solo algún ejemplo, le reprocha a una muchacha que suspira por un joven trece años mayor: «iCómo puedes estar «enamoradísima» de un hombre con el que solo hablaste una vez? $\gg^{16}$, cuando unas semanas antes había aconsejado a otra mujer que estaba a punto de contraer matrimonio con un hombre al que no amaba que se casase con él:

«Estoy segura, segurísima, de que le va a salir de perlas, precisamente por eso de que cree que le va a salir mal. En cambio, esas bodas perfectas, en las que

15. RIVELLES, Amparito. «Consultorio sentimental». Primer plano, 601, 20 de abril de 1952. 16. RIVELLES, Amparito. «Consultorio sentimental». Primer plano, 496, 16 de abril de 1950. 
todo es felicidad a toneladas, luego, a veces, ocurre que la felicidad no era tanta, etc., etc. Estoy segura que [sic] va a terminar adorando a su primo.» ${ }^{17}$

Y esto lo afirma ella, quien había renunciado a una boda de 'película' con Alfredo Mayo.

Tampoco estas incoherencias son tan excepcionales respecto a otros consultorios, ya que «el lenguaje estereotipado y evasivo, de medias tintas», «de tira y afloja», asomaba en ellas con frecuencia (Martín Gaite, 2002: 166). Esta era igualmente una característica predominante en este tipo de secciones publicadas en la Italia fascista, según constata Victoria de Grazia (1993: 133), quien describe que los consejos que se daban a las jóvenes combinaban la visión romántica con un duro cálculo sobre los beneficios del cortejo, prescribían qué estaba permitido en la vida amorosa y qué era ilícito, qué pasos podían atreverse a dar y cuáles solo ser soñados.

A menudo, da la sensación de que son las características del remitente y el propio tono de la consulta aquello que guía su reacción. O tal vez sea que no quiera comprometerse, que sus opiniones sean muy volubles o simplemente que no se lo llega a tomar muy en serio. Sean cuales sean las razones, esto último se antoja meridiano. En la entrevista antes reseñada acerca de su labor en el consultorio, queda ya patente que mientras que la periodista formula preguntas pertinentes, ella responde, como por otra parte acostumbra a hacer en sus encuentros con la prensa, con salidas chistosas que denotan una predisposición despreocupada ante un encargo que en otros medios se envuelve de solemnidad. Por si hubiera dudas, en uno de los consultorios introduce una nota final que deja claras sus intenciones:

«Este consultorio es más bien para consultas sencillas de índole sentimental, pero no trascendental. ¿Entendido? Queda ampliado hasta la receta de belleza; si es preciso la moda y la decoración. No se contestarán todas aquellas consultas de tipo moral, por considerarlas demasiado serias para esta sección.» ${ }^{18}$

Incluso parece ser que la propia dirección de Primer plano apoya este tono jocoso que frecuentemente adopta la columna, puesto que desde finales de 1950, el «Consultorio sentimental» se publica habitualmente en la página de la sección humorística o de miscelánea «Cortos animados». Cada vez parece más claro que su finalidad es el entretenimiento y no la educación sentimental y se escogen cartas más divertidas, como la de una chica que cuenta que no

17. RIVELLES, Amparito. «Consultorio sentimental». Primer plano, 482, 8 de enero de 1950. 18. RIVELLES, Amparito. «Consultorio sentimental». Primer plano, 505, 18 de junio de 1950. 
le deja en paz un chico que tiene «indigestión sentimental $»^{19} u$ otra que sufre enamoramientos relámpago y que está preocupada porque uno le dura ya día y medio ${ }^{20}$. En sus respuestas tampoco faltan las bromas. Por ejemplo, a una aspirante a actriz, le recomienda que se procure un buen matrimonio y se case con un ingeniero, como, dice en otra ocasión, debiera haber hecho ella, o con un abogado del Estado. O mejor, con un fontanero, que probablemente gane más dinero ${ }^{21}$. Llega incluso a corregirse a sí misma el tono pontificador que ha adquirido en una respuesta y se reprende porque ya está «hablando como una anciana $»^{22}$.

Nada tiene que ver la orientación de este consultorio con otros, como el de Elena Francis, que se presenta como «guía y consuelo para mujeres atormentadas», a las que dice ofrecer "consejos sensatos y acertados». La consejera se definía ante sus oyentes como una buena católica, de infinita dulzura, de gran corazón, comprensiva, amable... y establecía con ellas una relación maternofilial (Balsebre y Fontova, 2018: 120-121). Como no existe un sentido trágico en las cartas, al menos en las seleccionadas para su publicación, no hay ocasión de comprobar si recomienda abnegación y sacrificio ante el infortunio, como es habitual en este tipo de textos. Los problemas son banales, ya que quienes escriben expresan más los desencantos e inseguridades de la adolescencia que situaciones más graves que puedan darse en la convivencia marital.

No obstante, Amparo Rivelles no deja de mostrar su lado más tierno y comprensivo hacia cartas en las que se vislumbra que detrás hay alguien que sufre, aunque sea por ese tipo de nimiedades sobre las que se asentaban los preliminares de las relaciones entre los chicos y chicas: «Eres demasiado joven para dar tantísima importancia a esta cuestión sentimental, que a ti te parece ahora tan confusa y que el día de mañana te hará reír ${ }^{23}$.

De hecho, otra de las características de la columna, consecuencia de la bisoñez de los remitentes seleccionados, es la liviandad de los temas que se plantean. No hay lugar, pues, para problemas reales de pareja, como pueda suceder en otros consultorios abiertos a relaciones más maduras, ni por supuesto para dudas sobre el racionado acercamiento físico entre los novios, ni ningún asunto que pudiera calificarse de escabroso. Y si las hubo, no fueron seleccionadas.

19. RIVELLES, Amparito. «Consultorio sentimental». Primer plano, 582, 9 de diciembre de 1951.

20. Ibídem.

21. RIVELLES, Amparito. «Consultorio sentimental». Primer plano, 395, 9 de mayo de 1948.

22. RIVELLES, Amparito. «Consultorio sentimental». Primer plano, 402, 27 de junio de 1948.

23. RIVELLES, Amparito. «Consultorio sentimental». Primer plano, 391, 11 de abril de 1948. 
La mayoría de las preguntas tratan sobre la conquista, por utilizar el lenguaje bélico tan propio de la época como metáfora del flirteo, o los primeros pasos juntos de los enamorados. Como era corriente en otros consultorios, se ofrecían consejos que las madres no podían proveer, acerca de los tipos de hombres, de las clases de besos o el galanteo. En definitiva, sobre la negociación con el sexo opuesto, que muchas veces se convertía en una competitiva disputa entre unos y otras (De Grazia, 1993: 134).

Asimismo, encontramos incongruencias claras en relación con quien suscribe los consejos, pues basta conocer un tanto la trayectoria de Amparo Rivelles para comprender que frecuentemente no cumple con aquello que predica. Así, es reseñable que anime a sus fans a entablar un noviazgo encaminado hacia el matrimonio, cuando parece que ella rehúye de toda relación estable y que probablemente sus romances estarían en boca de muchos. Apuesta a menudo por las formalidades, mientras que conduce su vida sentimental sin acoplarse estrictamente a los códigos convencionales. Tal vez sea que no es lo mismo tener un modo de vida no acorde con la ortodoxia, que hacer apología de este. Si bien en alguna ocasión despotrica contra el exceso de formalidad que se ha instaurado en torno al cortejo.

«¿Cuántas veces voy a decir que eso de la declaración es un mito? El ochenta por ciento de los matrimonios que andan por el mundo no se hicieron esa función de la declaración. De pronto, los dos a la vez descubrieron que se querían mucho, se pusieron muy cursis, y en seguida hicieron proyectos para empezar a comprarse un comedor, con aparador y todo.» ${ }^{24}$

Quizá por ello con frecuencia solo parece ser sincera cuando adopta una postura sarcástica, que conecta mejor con sus propias manifestaciones públicas en torno a cuestiones como el matrimonio. Resulta más impostada cuando receta a una pareja cándidos paseos para conocerse o agradece a un chico que le haya enviado oraciones, que cuando aconseja con sorna a una jovencita cazar a un ingeniero o un universitario o cuando se ríe de un fan enamoradizo que le escribe cursilerías. Algunas de sus propuestas recuerdan situaciones disparatadas propias de una comedia cinematográfica, en la que los noviazgos son fugaces. Por ejemplo, insta a tres colegialas a que propicien el encuentro con un chico utilizando un perro o un niño:

«Como veis, es bien fácil: o perro o hermanito pequeño, de esos que se escapan de la mano para irse con los demás: para que la cosa salga mejor, procurad al pasar junto al chico empujar un poquito al nene para que se caiga, y ya

24. RIVELLES, Amparito. «Consultorio sentimental». Primer plano, 462, 21 de agosto de 1949. 
veréis, si es fino, cómo se apresura a coger al peque y a deciros eso: "no, si no es nada; este niño es un valiente". Y lo demás ya está de vuestra parte y de vuestra gracia» ${ }^{25}$.

Cabe recordar que en buena medida la imagen que las lectoras tendrían forjada de la estrella se correspondería con sus interpretaciones en la pantalla. El cine era un referente ejemplificador. Elena Francis utilizaba iconos como el de Gilda para anatemizar contra la femme fatale (Balsebre y Fontova, 2018: 145-147) y Meridiano femenino advertía contra la mala influencia de la representación de 'la mujer moderna' en el cine (Medina Doménech, 2013: 55-58). Sin embargo, Rivelles a una lectora que firma como Gilda le anima a que «practique los encantos propios de su nombre, y ya va bien servida» ${ }^{26}$.

En el de Primer plano se impone el estilo de la comedia romántica frente al drama, a veces con su mismo aire de irrealidad, de flechazos fulgurantes y de amor a primera vista, de las películas de enredo que tanto éxito de público cosecharon a principios de los cuarenta. Estaban ambientadas en viviendas burguesas y salas de fiesta, donde pululaban personajes excéntricos y despreocupados, para quienes la vida era sobre todo ocio y diversión. Un género de entretenimiento y evasión que sintonizaba con los arquetipos y pautas de comportamiento que el Régimen quería transmitir, aunque introducían un marco de frivolidad desde el que se podía establecer una vía de rechazo al discurso oficial (Rincón Díez, 2014: 77-128).

Amparo Rivelles se revela como una autoridad en diferentes materias, pero especialmente en el amor, probablemente porque se constata en estas cartas la profunda ignorancia mutua entre hombres y mujeres. Los avances en la vulgarización del saber sobre el sexo que se dio durante los años veinte y la II República fueron borrados por el franquismo. Se impuso un discurso represivo, basado en la tradición, que propugnaba que al amor solo se llegaba con el matrimonio, y en el que la finalidad exclusiva del encuentro carnal de los cónyuges era la procreación. No había pues que confundirlo con la mera atracción, y para ello servía el noviazgo, que se caracterizaba por la amistad amorosa y la templanza en las relaciones físicas (Regueillet, 2004). Es cierto que en los años treinta estaba asentada la idea entre las clases medias de que el matrimonio era el horizonte vital de las jóvenes (Llona, 2002: 42), y es predecible que así seguiría siéndolo en la década siguiente. Pero la realidad es que el proceso de aproximación entre chicos y chicas era en muchos casos penoso.

25. RIVELLES, Amparito. «Consultorio sentimental». Primer plano, 491, 12 de marzo de 1950.

26. RIVELLES, Amparito. "Consultorio sentimental». Primer plano, 425, 5 de diciembre de 1948. 
Se habían educado en ámbitos distintos y estancos y apenas nada sabían los unos de las otras, y viceversa. Ellos sumidos en el marasmo de confusiones por su obligación de tomar la iniciativa en el cortejo (Torres, 2002: 59), mientras la joven asistía desconcertada a la desesperante timidez de su pretendiente, que no se atrevía a declarársele. Ante tal inoperancia, y quizá bajo la misma influencia del cine, la comunicación no verbal se convirtió en una herramienta indispensable para desentrañar los sentimientos que subyacían bajo la pasividad. Entre ellas, la mirada, cuya sutil interpretación requería de una práctica empírica para su correcto discernimiento. Y no menos filigranas se necesitaban para saber responder a ese tácito requiebro, sin transgredir los mandatos de inacción demandados a las mujeres (Medina Doménech, 2013:224-226).

Por tanto, el papel de la consejera adquiere en esta tesitura una gran importancia para superar las incertidumbres. A unos y a otras, Rivelles anima a dar un paso adelante. A ellos les da consejos prácticos de cómo promover encuentros e iniciar conversaciones, y a ellas, a tomar las riendas de la situación si es necesario, al igual que otras veces les insta a no dejarse engañar por la imperturbabilidad que esconde una falta de interés verdadero. Una actitud más proactiva que solían promover los consultorios de las revistas femeninas, que también dedicaba un espacio amplio a resolver las inquietudes provocadas por cómo interpretar el comportamiento masculino. Estas publicaciones, a las enamoradas, las tranquilizaban y orientaban hacia una posición pasiva o las consolaban y trataban de reforzar su autoestima (Muñoz Ruiz, 2003).

Otro problema que sale a menudo a colación en la columna es el de los complejos que impiden a los jóvenes ser felices, fundamentalmente por la disconformidad con sus propios cuerpos.

«Lo peor que te pasa a ti es que ni tú misma te tienes simpatía; te quieres poco. Lo tuyo no es un problema físico, sino de espiritualidad: estas acobardada porque te crees una birria o te lo han hecho creer los que te rodean. Verás: esa gordura estoy segura que [sic] desaparece con un plan que te ponga el médico, los granitos de la cara, igual. En cuanto a esa miopía (...) Serás otra mujer en el momento que venzas ese terrible complejo de inferioridad que te domina de ese modo y que te va a hacer una desgraciada. $»^{27}$

En estos casos, hay que valorar la actitud que toma Rivelles, que siempre les alienta a superarlos y que alguna vez, en un tono desenfadado, reconoce que ella tiene problemas con la báscula. Seguramente sus confesiones agradarían a muchas de sus seguidoras, que les consolaría que una de las mujeres más deseadas del país compartiera con ellas las inseguridades sobre su físico.

27. RIVELLES, Amparito. «Consultorio sentimental». Primer plano, 393, 25 de abril de 1948. 
Cuando los padres se oponen a la relación, Rivelles no toma partido contra autoridad familiar ni empuja a desafiarla, con expresiones como «los padres saben siempre más que nosotros $»^{28} u$ otras menos rotundas:

«El amor es como una locomotora loca, que lo arrolla todo. Si no estás muy enamorada todavía, podías recapacitar un poquito y ver si verdaderamente el muchacho merece la pena; no vaya a ser que tu familia tenga razón. $»^{29}$

No obstante, a una chica de dieciséis años cuyos padres la consideran demasiado joven para tener novio, le aconseja llevarlo en secreto, porque será más excitante $^{30}$.

Suele apostar por el punto de vista femenino, y la resignación ante actitudes masculinas poco gratificantes no la contempla como una opción.

«Si tienes interés por éste, yo creo que nada mejor para que aprenda que dejarle plantado en medio de la calle, en el cine, en el tranvía, cada vez que te nombre a tu primer novio. Si te quiere, verás qué buenísimo resultado te da. Ahora, piénsalo bien, y si de verdad no estás muy por éste, déjalo en paz ¡para qué tomarse molestias! $»^{31}$

«Me horroriza pensar qué hará el día que tenga motivo de verdad para estar celosa. Hay que calmar esos celos; si no, ese pobre hombre se va a desesperar, y con razón. ¿Está segura de que no tiene motivos para estar celosa? No sé por qué me da el corazón que su novio le da más disgustos que otra cosa. Si no le conviene mucho, déjelo.» ${ }^{32}$

Deja entrever que frente a la figura tradicional del donjuán, que el discurso médico, como el formulado por Gregorio Marañón, ya había criticado como modelo de masculinidad (Aresti, 2001), aspira a un ideal de compañero, basado en la compenetración emocional, en la línea de las ilusiones femeninas de transformación de las relaciones amorosas que se plantearon en los años veinte y treinta, aunque no llegaran a asentarse (Llona, 2007).

A los chicos más jóvenes, los impele a no desfallecer en los estudios y a seguir una carrera universitaria. Unas veces apuesta por el matrimonio como estabilidad económica, y otras, por el amor romántico; pero tampoco faltan las ocasiones en que tacha las vicisitudes que le confiesan como historias de folletín, aunque ora las alienta, ora se mofa de ellas.

28. RIVELLES, Amparito. «Consultorio sentimental». Primer plano, 406, 25 de julio de 1948.

29. RIVELLES, Amparito. «Consultorio sentimental». Primer plano, 395, 9 de mayo de 1948.

30. RIVELLES, Amparito. «Consultorio sentimental». Primer plano, 535, 14 de enero de 1951.

31. RIVELLES, Amparito. «Consultorio sentimental». Primer plano, 410, 22 de agosto de 1948.

32. RIVELLES, Amparito. «Consultorio sentimental». Primer plano, 414, 19 de septiembre de 1948. 
«Si la chica no es de su igual, como me da a entender en su consulta, la mejor manera de vencer para usted es olvidarla. No sería feliz, se lo aseguro. Ahora, si tan enamorado está de ella y verdaderamente no puede vivir sin su cariño, y si esto les sirve como acicate para tener fe en la vida y crear un porvenir, entonces luche y procure vencer. $»^{33}$

«Hija mía, con lo carísimos que están hoy los novios, ni lo dudes; hazle cara al del pueblo; ese está cerca y es más fácil controlarlo. Al otro, ni vuelvas a pensar en el: el hombre qué tiene un compromiso con una mujer y deja de escribirla un mes, no merece más que el desprecio de ésta.» ${ }^{34}$

En cualquier caso, nada similar a los valores de sumisión, obediencia, servicio y sacrificio, que proponía a las mujeres la revista Medina, editada por la Sección Femenina de Falange entre 1941 y 1945. Unas máximas que se aplicaban tanto a la vida pública como privada. En su sección «Consúltame», abogaba por el recato, el pudor y la prudencia, y desaprobaba la insinuación femenina como medio para atraer a los hombres (Pinilla García, 2006).

El último consultorio sentimental firmado por ella es el del número 619 de Primer plano, publicado el 24 de agosto de 1952, sin que mediara explicación alguna sobre su desaparición, a pesar de la dilatada presencia en la revista. En 1953, la sección es recuperada. La nueva consejera es Elena Espejo, una actriz de mucho menor fuste, en absoluto comparable a la personalidad arrolladora de Rivelles. Ello se traduce en que, a pesar del encabezado de la sección, el consultorio ya no es realmente sentimental, sino que las preguntas acostumbran a versar sobre cuestiones relacionadas con la profesión actoral o la carrera de la autora. Da la impresión de que implícitamente se reconoce que Elena Espejo carece de la autoridad de su antecesora y, de hecho, la sección acabará languideciendo poco a poco.

\section{Conclusiones}

Por cuanto se ha ido señalando, se puede concluir que el consultorio sentimental de Amparo Rivelles se revela como un caso singular en la dictadura franquista de la posguerra. No era habitual que una publicación de la Cadena del Movimiento, como era el semanario cinematográfico Primer plano, eligiese a una personalidad de la farándula como consejera para la juventud. Mucho menos, cuando se trata de una estrella que, si bien no puede calificarse de públicamente transgresora respecto a los códigos morales impuestos y promovidos

33. RIVELLES, Amparito. «Consultorio sentimental». Primer plano, 398, 30 de mayo de 1948.

34. Ibídem.

Pasado y Memoria. Revista de Historia Contemporánea, 23, 2021, pp. 260-282 
por el Régimen, ni era una de sus propagandistas ni tan siquiera parecía acatarlos fielmente.

Podría argumentarse que no nos encontramos en puridad ante un consultorio sentimental stricto sensu, sino ante un divertimento liviano. Sin embargo, ello tampoco restaría un ápice de importancia al hecho de que la censura tolerase la publicación de una versión cómica y anecdótica de un espacio periodístico que en otros ámbitos se consideraba fundamental. Sin olvidar que a menudo entre estos textos se confunden las bromas y las veras, la guasa y las admoniciones, la empatía y el descreimiento, la asunción de una actitud irónica por parte de la consejera y su ofrecimiento de comprensión y ayuda. Para el franquismo, la educación sentimental de los españoles y de las españolas, sobre todo de estas últimas, no era un asunto para tomárselo en absoluto a la ligera, y menos aún para dejarlo en manos de una descollante personalidad tan aparentemente voluble o imprevisible.

No es necesario insistir en que todo cuanto aquí se ha expuesto no puede reducirse a un análisis micro de las columnas publicadas; sino que tiene que ser insertado en el contexto histórico político, social y cultural del primer franquismo, y de cuanto representaba la imagen estelar de Amparo Rivelles. Es en este diálogo entre discursos donde debe ser analizado, de manera que se constituye en un elemento más que pone en evidencia las tensiones y contradicciones provocadas por las políticas franquistas de género.

En este sentido, Amparo Rivelles se nos aparece como un modelo heterodoxo de feminidad, que no cumplía con los principios de domesticidad y subordinación con los que el Régimen pretendió someter al conjunto de mujeres. Bien es cierto de que era una joven en una posición de privilegio, económico y personal, otorgado por su misma condición de estrella cinematográfica. Asimismo, se movía en un mundo en el que se había instalado el discurso de unos usos amorosos tradicionales y burgueses, que el Régimen tomó como pilares de sus códigos normativos acerca del noviazgo y de la sexualidad. No obstante, el grado de aceptación e interiorización de dichas normas fue diverso (Regueillet, 2004), aunque la capacidad de decisión sobre ellas estaba sometida al escrutinio y la sanción social, y por consiguiente al silencio.

El discurso moral que se deduce de estos textos firmados por Amparo Rivelles no alentaba siempre el cumplimiento de las formalidades y convencionalismos establecidos, aunque tampoco resultaba claramente disruptivo. Un discurso que, sin embargo, sí chocaba con su propia trayectoria vital, mucho más libre de corsés, o contra el que encarnaban algunos de los personajes que interpretó en sus películas. El hecho de que se le concediese un altavoz para confirmar mediante la palabra escrita aquello que ya se insinuaba en la 
pantalla y en su presencia en los medios periodísticos es un motivo digno de ser tenido en cuenta.

\section{Bibliografía}

ÁLVAREZ RODRIGO, Álvaro (en prensa). Fisuras en el firmamento. El desafío de las estrellas de cine al ideal de feminidad del primer franquismo. Valencia: Publicacions de la Universitat de València.

ARESTI, Nerea (2001). Médicos, donjuanes y mujeres modernas: Los ideales de feminidad y masculinidad en el primer tercio del siglo XX. Bilbao: Universidad del País Vasco.

BALSEBRE, Armand y FONTOVA, Rosario (2018). Las cartas de Elena Francis: Una educación sentimental bajo el franquismo. Madrid: Cátedra.

BLANCO FAJARDO, Sergio (2016). Los consultorios sentimentales de radio durante el primer franquismo. A propósito del programa «Hablando con la esfinge» (1946-1956). Arenal: Revista de historia de las mujeres, 23, 59-83.

BUCKLEY, Réka (2009). The emergence of film fandom in postwar Italy: Reading Claudia Cardinale's fan mail. Historical Journal of Film, Radio and Television, 29, 523-559. https://doi.org/10.1080/01439680903363222

DE GRAZIA, Victoria (1993). How fascism ruled women: Italy, 1922-1945. Berkeley: University of California Press.

DE GRAZIA, Victoria (1996). «Empowering women as citizen-consumers» En Victoria DE GRAZIA y Ellen FURLOUGH (eds.). The sex of things: Gender and consumption in historical perspective (275-286). Berkeley: University of California Press.

DI FEBO, Giuliana (2005). La cuna, la cruz y la bandera. Primer franquismo y modelos de género. En Isabel MORANT (ed.). Historia de las mujeres en España y América Latina. vol. IV (217-237). Madrid: Cátedra.

DYER, Richard (2001). Las estrellas cinematográficas: Historia, ideología, estética. Barcelona: Paidós.

FANÉS, Félix (1982). Cifesa: La antorcha de los éxitos. Valencia: Institución Alfonso el Magnánimo.

GARIS, Ana Victoria (2010). Corazones en conflicto. El consultorio sentimental en Argentina (1920-1975). La trama de la comunicación, 14, 123-149. https:// doi.org/10.35305/lt.v14i0.3

KUHN, Annette (2002). Dreaming of Fred and Ginger: Cinema and cultural memory. New York: New York University Press.

LABANYI, Jo (2016). Feminizing the nation: Women, subordination and subversion in post-civil war Spanish cinema. En Ulrike SIEGLOHR (ed.). Heroines without heroes: Reconstructing female and national identities in European cinema, 1945-51 (163-182). London: Bloomsbury. 
LLONA, Miren (2002). Entre señorita y garçonne: Historia oral de las mujeres bilbaínas de clase media, (1919-1939). Málaga: Universidad de Málaga.

LLONA, Miren (2007). Los otros cuerpos disciplinados: Relaciones de género y estrategias de autocontrol del cuerpo femenino (primer tercio del siglo XX). Arenal: Revista de historia de las mujeres, 14, 79-108.

MARTÍN GAITE, Carmen (2002). Usos amorosos de la postguerra española. Barcelona: Anagrama.

MEDINA DOMÉNECH, Rosa María (2013). Ciencia y sabiduría del amor: Una historia cultural del franquismo (1940-1960). Madrid: Iberoamericana. https:// doi.org/10.31819/9783954870783

MULVEY, Laura (2001). Placer visual y cine narrativo. En Brian WALLIS (Ed.). Arte después de la modernidad: Nuevos planteamientos en torno a la representación (365-377). Madrid: Akal.

MUÑOZ RUIZ, María del Carmen (2003). La construcción de las relaciones de género en el franquismo y sus conflictos: Los consultorios sentimentales. Arenal: Revista de historia de las mujeres, 10, 219-239.

NIETO FERRANDO, Jorge (2009). Cine en papel: Cultura y crítica cinematográfica en España: (1939-1962). Valencia: Filmoteca Valenciana.

PINILLA GARCÍA, Alfonso. (2006). La mujer en la posguerra franquista a través de la revista Medina (1940-1945). Arenal: Revista de historia de las mujeres, 13, 153-179.

REGUEILLET, Anne-Gaelle. (2004). Norma sexual y comportamientos cotidianos en los diez primeros años del franquismo: Noviazgo y sexualidad. Hispania: Revista española de historia, 64, 1027-1042. https://doi.org/10.3989/hispania.2004.v64.i218.178

RINCÓN DÍEZ, Aintzane (2014). Representaciones de género en el cine español (1936-1982): Figuras y fisuras. Madrid: Centro de Estudios Políticos y Constitucionales.

ROURA, Assumpta (2005). Un inmenso prostíbulo: mujer y moralidad durante el franquismo. Barcelona: Base.

SÁNCHEZ SÁNCHEZ, Pura. (2013). Escribir de emociones desde la emoción. Las cartas de los consultorios femeninos. Revista electrónica de psicología Iztacala, 16.

SOTO VIÑOLO, Juan (1995). Querida Elena Francis. Barcelona: Grijalbo Mondadori.

STACEY, Jackie (1991). Feminine fascinations: Forms of identification in star-audience relations. En Christine GLEDHILL (ed.). Stardom: Industry of desire (141-163). New York: Routledge. https://doi.org/10.4324/9780203400425_chapter_12

STACEY, Jackie (1994). Star gazing: Hollywood cinema and female spectatorship. London: Routledge.

TORRES, Rafael (2002). El amor en tiempos de Franco. Madrid: Oberon. 